\title{
Investigation of temperature effect on the electrical conductivity of solutions inorganic salts in ethanol
}

\author{
(C) Vera A. Petrukhina, Ksenia A. Konnova, \\ Maria V. Yakimova, and Nikolay I. Koltsov* ${ }^{+}$ \\ Department of Physical Chemistry and Macromolecular Compounds. \\ I.N. Ulyanov Chuvash State University. Moskovsky Ave., 15, Cheboksary, 428015. \\ Chuvash Republic.Russia.Phone:+7(352)45-24-68.E-mail: koltsovni@mail.ru
}

\begin{abstract}
*Supervising author; ${ }^{+}$Corresponding author
Key words: solutions inorganic salts in ethanol, specific and equivalent electrical conductivity, temperature, Arrhenius equation.
\end{abstract}

\begin{abstract}
The electrical conductivity of the solutions depends on the nature of the solute and solvent. For a solvent, the main parameter is the dielectric constant. Since the dielectric constant of alcohols is much less than the dielectric constant of water, the electrical conductivity of alcoholic solutions of salts is less than the electrical conductivity of their aqueous solutions. Therefore, alcoholic solutions of inorganic salts are weak electrolytes. We previously studied the electrical conductivity of inorganic salts in a number of alcohols (ethanol, propanol-2 and butanol-1) at room temperature. It is of interest to study the effect of temperature on the electrical conductivity of salts in alcohols. Obviously, an increase of temperature salt solutions leads to an increase in their electrical conductivity. To study the temperature dependence of the electrical conductivity of aqueous solutions electrolytes, we proposed an approach based on the study of the effect of temperature on the equivalent electrical conductivity of solutions at infinite dilution $\lambda_{\infty}$. Using this approach, we studied the electrical conductivity of aqueous solutions of a number of inorganic salts, carboxylic acids, and amino acids as a function of temperature. It has been established that for these solutions the dependence $\lambda_{\infty}(T)$ is described by the exponential Arrhenius equation $\left.\lambda_{\infty}=\mathrm{A} \cdot \exp (-\mathrm{E} / \mathrm{RT})\right)$. However, such studies have not been conducted for alcoholic salt solutions. In this regard, this article explores the possibility of describing the experimental data $\lambda_{\infty}(T)$ for solutions of certain inorganic salts in ethanol by this equation. It is shown that the Arrhenius equation with the found activation energies adequately describes the temperature dependence of the ultimate equivalent conductivity for solutions of a number of inorganic salts (chloride and calcium nitrate, cadmium iodide, lithium and potassium chloride, chloride, iodide and ammonium nitrate, silver nitrate and sodium bromide) in ethyl alcohol.
\end{abstract}

\section{References}

[1] V.A. Petruhina, T.A. Kurnaleva, D.A. Egorova, and N.I. Koltsov. Investigation of the influence of temperature on electrical conductivity of aqueous solutions of electrolytes. Part 1. Strong electrolytes. Butlerov Communications. 2016. Vol.45. No.1. P.107-109. DOI: 10.37952/ROI-jbc-02/16-45-1-107

[2] V.A. Petruhina, T.A. Kurnaleva, D.A. Egorova, A.S. Vasileva, and N.I. Koltsov. Investigation of the influence of temperature on electrical conductivity of aqueous solutions of electrolytes. Part 2. Weak electrolytes. Butlerov Communications. 2016. Vol.45. No.1. P.110-112. DOI: 10.37952/ROI-jbc-02/16-45$1-110$

[3] V.A. Petrukhina, E.V. Andreeva, and N.I. Koltsov. Investigation of the influence of temperature on electrical conductivity of aqueous solutions of electrolytes. Part 3. Nitrates. Butlerov Communications. 2017. Vol.49. No.1. P.104-107. DOI: 10.37952/ROI-jbc-02/17-49-1-104

[4] V.A. Petrukhina, E.V. Andreeva, and N.I. Koltsov. Investigation of the influence of temperature on electrical conductivity of aqueous solutions of electrolytes. Part 4. Acetates and phosphates. Butlerov Communications. 2018. Vol.53. No.2. P.140-144. DOI: 10.37952/ROI-jbc-02/18-53-2-140

[5] E.N. Egorov, N.F. Ushmarin, S.I. Sandalov, I.S. Spiridonov, and N.I. Koltsov. The influence of functional ingredients on the technological properties of oil swelling rubber sealing elements. Butlerov Communications. 2018. Vol.54. No.5. P.159-164. DOI: 10.37952/ROI-jbc-02/18-54-5-159 
INVESTIGATION OF TEMPERATURE EFFECT ON THE ELECTRICAL CONDUCTIVITY OF SOLUTIONS..._ 76-80

[6] V.A. Petrukhina, P.I. Fedorov, T.A. Kirillova, L.Yu. Tcareva, E.V. Andreeva, and N.I. Koltsov. Study of the effect of temperature on the electrical conductivity of aqueous solutions of amino acids. Butlerov Communications. 2019. Vol.57. No.1. P.91-94. DOI: 10.37952/ROI-jbc-02/19-57-1-91

[7] V.A. Petrukhina, T.A. Kirillova, L.Yu. Tcareva, E.V. Andreeva, and N.I. Koltsov. The study of electrical conductivity of spirit solutions of salts. Butlerov Communications. 2019. Vol.57. No.1. P.154-158. DOI: 10.37952/ROI-jbc-02/19-57-1-154 